\title{
Land Robotic Vehicles for Demining
}

\author{
Štefan Havlík \\ Institute of Informatics, Slovak Academy of Sciences \\ Slovakia
}

\section{Introduction}

The idea of using mechanical equipments and vehicles for demining operations is dated since the First World War. At the same time several explosion activating mechanisms, including flails, were designed and tested. There were two main reasons. Preferably, it was the military demand to perform demining operation by a faster way in order to protect passage of army troops. The development of the demining technology for cleaning the post battle fields and protection of civilians was the interest of second order, only. This opinion was continuing during the Second war, practically till the end of 1970s. During this period no important progress and principal changes as to demining technology were observed. It was more-less standard concept: a roller, tiller or a rotating flail shaft pushing if front of a heavy vehicle, most frequently the tank. After this period, further development and mass production of cheap mines as well as they deployment have resulted in fact that mines became the real psychological weapon witch suffer mainly civilians. Unfortunately, the large amount of mines, especially anti/personnel, are still deployed and still used in some conflict areas. This fact confirms number of victims and injuries due to accidental explosions ธิ of mines abandoned on post-battle fields.

Classic methods for detection and removing mines are dangerous, too costly and considering the number of abandoned mines, are very slow. Within technologies for demining large mine polluted areas most frequently used are mechanical systems. Usually a pressure is acting on the ground by rollers pushed ahead of a tank or rotary flails beating the ground, or, the mines are dug out and pressed by a rake. Main drawback of this purely mechanical demining is that no system can satisfy the desired $100 \%$ reliability of humanitarian mine cleaning. For this reason manual verification of cleaned area is required.

\& Following the development of vehicles for demining, especially humanitarian, the acceleration and progress can be seen after 1980s. This was naturally influenced by development and progress in robotics, detection systems, computing, communication and control, as well as related technological domains. Some available technologies that can be used for demining are more exactly elaborated and, beside yet known techniques, new d principles are designed and widely studied. Despite this effort concepts of remotely operated vehicles combining mechanical activation techniques are most widely used (Habib, 2002; Licko \& Havlik, 1997; GICHD, 2004; Lindman \& Watts, 2003; Ide et al., 2004; Kaminski et al., 2003; Stilling et al., 2003). Actually, there are more then 30 manufacturers of machines for this purpose listed in catalogue (GICHD, 2006). For performance evaluation of particular

Source: Humanitarian Demining: Innovative Solutions and the Challenges of Technology, Book edited by: Maki K. Habib, ISBN 978-3-902613-11-0, pp. 392, February 2008, I-Tech Education and Publishing, Vienna, Austria 
machines the common criteria and test conditions were accepted on the international level (CEN, 2004). According to these standards it is possible to compare machines available on market (Proc, 2007).

When we talk about robotic vehicles we have in mind some principal features that such a robotic vehicle for demining should exhibit. There are:

- It is unmanned vehicle which moves and works in the minefield automatically, or, remotely controlled.

- The vehicle is equipped by on board manipulation systems (robot arm, manipulator).

- Using detection systems and sets of special tools for manipulation systems enable to perform three principal tasks of the demining process: searching / detection, preparing terrain, neutralization.

As obvious, the vehicle should be provided by sensory equipment that enables some level of autonomy in performing particular tasks. Keeping the reality and in order to show the development of such kind of vehicles the „Božena” family machines will be followed; as one example for the purpose of this article.

\section{History and Experiences}

The development and building unmanned vehicles that could replace humans in making such dangerous works, as demining operations, was one of the first fields of interest since the beginning of advanced robotics. As proved the robotic demining technology can be successfully applied in searching process, as well as neutralization of mines. After more then twenty years of development, production and using flailing vehicles in many regions lot of experiences, as regards to their further development, have been gained. First vehicles "Božena 1" developed before 1995 and produced within next five years were verified in real conditions and have been used by demining companies and military peace forces for cleaning the post battle minefields in several countries (Ličko \& Havlík, 1997).

The primary concept of the vehicle, in Fig. 1, represents a modification of the small loader i.e. machine for manipulation with loose materials, terrain works, etc. The flailing activation mechanism based on rotating chains with hammers on their ends is fixed on the end flange of the hydraulically powered mechanism. The radio communication system enables remote mobility control, manipulation with activating mechanisms as well as monitoring relevant parameters of the whole system.

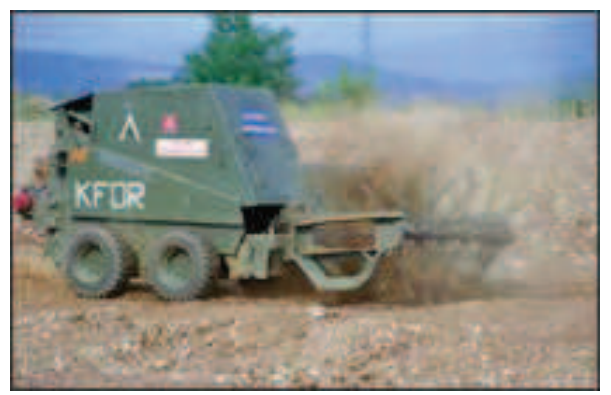

Fig. 1. The remotely operated flailing vehicle "Božena 1" 
Next generations of these mini-flail machines "Božena 2 and 3", as shown in Fig. 2 have been produced within 2000-2002. They exhibit more powerful driving unit, better maneuvering and control capabilities and, due to more available power, more reliable activation by flailing was reached.
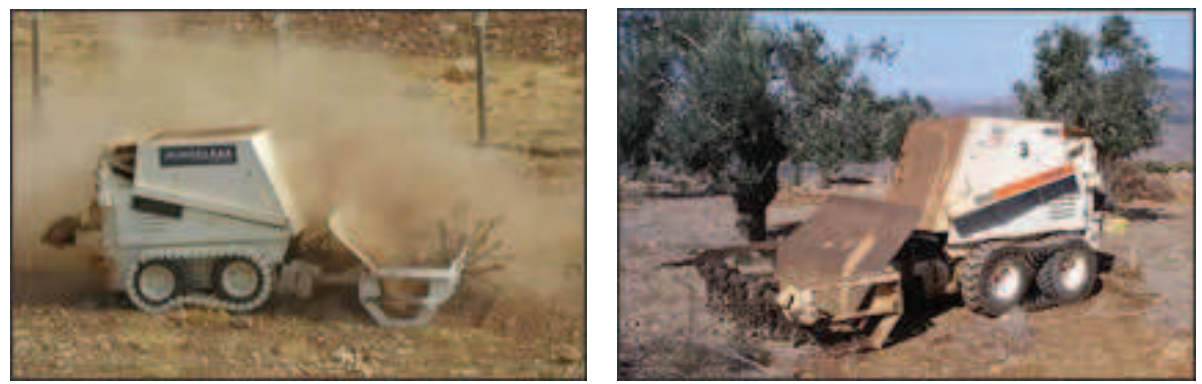

Fig. 2. The mini-flail vehicles "Božena 2 and 3"

Further development of these machines represents important design changes, improvement of their performances and more operation applicability as well. The latest generations of these machines and more detailed description of is given in next section.

As confirmed experience the remotely operated flailing vehicles exhibit some important advantages. There are:

- Fast speed and high productivity in performing cleaning operation. Comparing to classical hand demining procedures the system based on mechanical flailing technology is minimally 10 times faster.

- Low cost and high efficiency of the system especially when infected terrain is covered by grass or small vegetation. Flailing technology is especially suited for cleaning large areas where mines can be hardly detected due to terrain and vegetation.

- Universal technical solution of the system based on multipurpose soil machines, as small loaders. The loader and maneuvering unit can be combined with several additional attachments can be used for demining process. Such concept guarantees availability of spare parts, verified reliability and good maintenance.

- Relatively low weight, fast and low cost transport to the place of use is highly required.

Results from more then fifteen years experience of using similar machines can be summarized into statements as follows:

- Application of purely mechanical destruction techniques and the flailing technique, as well, can not guarantee $100 \%$ reliability of cleaning terrain from mines and any explosives. Despite this fact the vehicle with flailing mechanisms is an effective tool especially in all cases when positions of mines are not exactly known, if the terrain is covered by vegetation, or, if there is another suspicion or some uncertainty. To satisfy maximal reliability the post verification of the cleaning process can be realized using vehicles equipped by mine detection systems.

- Using remotely operated vehicles minimizes psychological pressure and improves safety of persons. The useful help for operator is, if some functions are performed automatically, 
as for instance: flailing process with respect to advance speed, or, straight line control routines.

- The efficiency of the whole demining process will be improved if mines are previously detected and localized. Then, the destruction vehicle could be directly navigated to these positions where mines are expected.

To document and compare the productivity in performing cleaning of various terrains classified on three categories the verified parameters of the real mini-flail vehicle "Bozena 4" (WAY Industry, 2006) are given in Table 1.
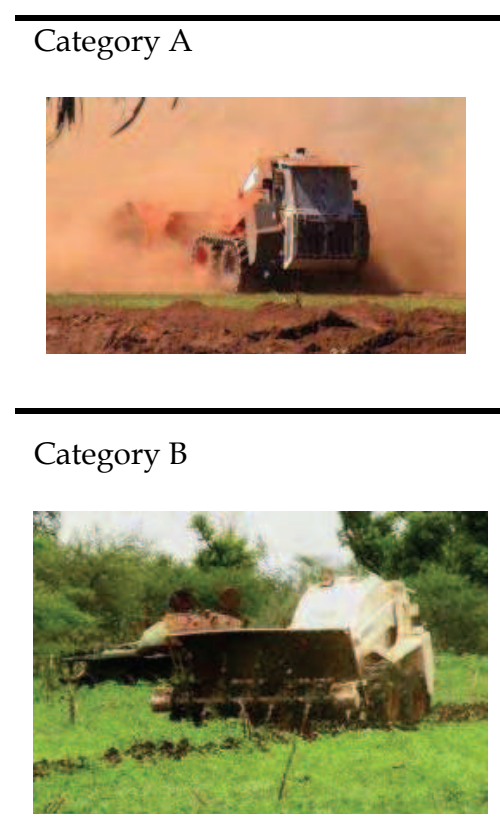

Cleaned area: $2500 \mathrm{~m}^{2} /$ hour

(12500 $\mathrm{m}^{2} / 5$ hour day)

Soil and Ground: dry topsoil, not too hard, without stones and boulders

Terrain: flat or with gentle slopes only

Vegetation: scarce, wet with max. $3 \mathrm{~cm}$ thick stems not higher than $1 \mathrm{~m}$

Obstacles: no trees, razor fences and no large refuse pile, other obstacles classified as "moderate"

Cleaned area: $1100 \mathrm{~m}^{2} /$ hour (5500 m² / day)

Soil and Ground: hard soil, partially stony or wet with scarce boulders

Terrain: flat or with moderate slopes up to $15^{\circ}$

Vegetation: moderate, wet $(\max .10 \mathrm{~cm}$ thick stems not higher than $1.5 \mathrm{~m}$

Obstacles: not too many trees, gaps between trees not less then $10 \mathrm{~m}$, not too many razor fences and refuse piles, other obstacles classified as "difficult"

Category C

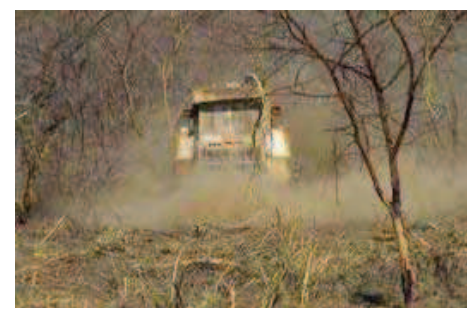

Cleaned area $520 \mathrm{~m}^{2} /$ hour $\left(2600 \mathrm{~m}^{2} /\right.$ day $)$

Soil and Ground: muddy and marshy, or very stony with large boulders

Terrain: very uneven surface with slopes over $20^{\circ}$, the machine stuck in mud at least once per day

Vegetation: dense and hard bushes higher than $1.5 \mathrm{~m}$, not higher than $1 \mathrm{~m}$, over $60 \%$ of cleared area, gaps between trees not less then $5 \mathrm{~m}$, not too many razor fences and refuse piles, other obstacles classified as "very difficult"

Table 1. Productivity of flailing vehicles 
As follows from experiences the vehicle should be constructed as a "multi purpose" machine able to perform various activities. Such approach could minimize cost of the vehicle and the whole system, as well.

\section{A Modular Concept}

The multi purpose remotely operated machine should able to perform beside demining tasks some other activities, as for instance: disaster rescue and anti-terrorist operations, or, several civil engineering works. This is the concept of the remotely operated vehicle with on board manipulation robotic mechanisms and sets of task oriented tools for performing particular tasks.

When analyze available demining technologies and technical possibilities one can relate functional requirements to on-board vehicle equipment and tools, as given in the next table.

\begin{tabular}{|l|l|l|}
\hline Task and minefield activities & Equipment / Tools & Robotic equipment \\
\hline Searching dangerous terrain & $\begin{array}{l}\text { Mine detection systems on } \\
\text { platform (mainly Ground } \\
\text { penetration radar - GPR) } \\
\text { Detectors on the end flange of } \\
\text { the long reach arm } \\
\text { Marking system of targets }\end{array}$ & $\begin{array}{l}\text { Heavy manipulator } \\
\text { Robot arm }\end{array}$ \\
\hline Neutralization by flailing & Flailing mechanism & Heavy manipulator \\
\hline $\begin{array}{l}\text { Post - cleaning verification, } \\
\text { removing metal parts, ... }\end{array}$ & Detection systems & Heavy manipulator \\
\hline $\begin{array}{l}\text { Cleaning vegetation } \\
\text { Strong magnets }\end{array}$ & Cutters, saws, ... & $\begin{array}{l}\text { Heavy manipulator, } \\
\text { Robot arm }\end{array}$ \\
\hline Removing mines, obstacles, ... & Grippers, suckers, & Robot arm \\
\hline $\begin{array}{l}\text { Neutralization by using } \\
\text { specific techniques: posing } \\
\text { explosives, burning and } \\
\text { others. }\end{array}$ & Grippers - special tools & Robot arm \\
\hline $\begin{array}{l}\text { Manipulation with soil and } \\
\text { loose materials: transport, } \\
\text { loading, digging, drilling, }\end{array}$ & Additional accessories / tools & Heavy manipulator \\
\hline
\end{tabular}

Table 2. Tasks and on board vehicle equipment and tools

As could be deduced from the above analysis and considering actually real possibilities these functional requirements can satisfy the common modular concept of mobile robotic system with as shown in Figs. 3 and 4 (Havlík, 2007).

- An all-terrain unmanned vehicle moving on wheels / belts with the maneuvering capability that corresponds to terrain conditions. The vehicle as porter of multi-sensorial system should exhibit very good maneuvering and control capability in various terrain as well as autonomy features, as collision avoidance, automatic stop in cases of detected mine, remote vision, etc. In case of the neutralization vehicle with similar maneuvering 
and control capabilities it has to approach to the position of a detected mine and to neutralize it by activation or removing. For this reason it has to be protected against explosions of mines (not only antipersonnel but anti-tanks too). One of successful solution seems to be flailing activation system and formed protection cover against pressure waves due to explosions. From the point of view mechanical performance there are several specific requirements that both vehicles should satisfy (maximal pressure on the ground, velocity related to speed of detection systems, noise and temperature limitation, reliable power and communication systems, self recovery capabilities, etc).

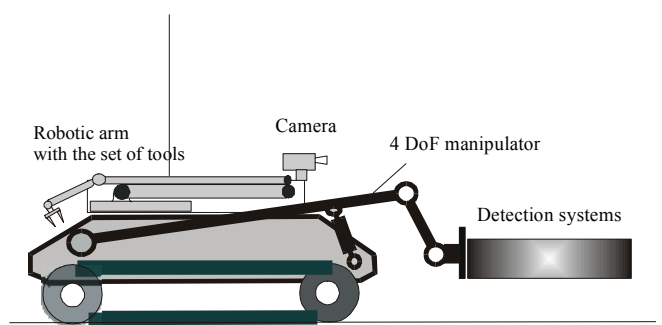

Fig. 3. A concept of the robotic vehicle for detection landmines

- A heavy 3 - 4 d.o.f. manipulator in front of the vehicle with about 1000 - $1200 \mathrm{~kg}$ payload capacity. The heavy weight manipulator is the main porter of heavy sensory systems as well as equipment for neutralization of mines (flail with protective cover), tools for cutting vegetation, etc.

- A long reach 6 d.o.f. robot arm: payload about $20 \mathrm{~kg}$ and reach distance approx. $3 \mathrm{~m}$. The long reach arm will be used for fine works as follows: removing / deployment neutralization explosives, probing, fine cutting the vegetation, localization of mines using additional detectors, etc.

- Sets of exchangeable tools and attachment for performing particular tasks. The set of tools consists of probes, cutters, various grippers, additional sensors for detecting explosives, etc. On the end of arm will be small camera what will allow detailed views on the mine and place of its vicinity.

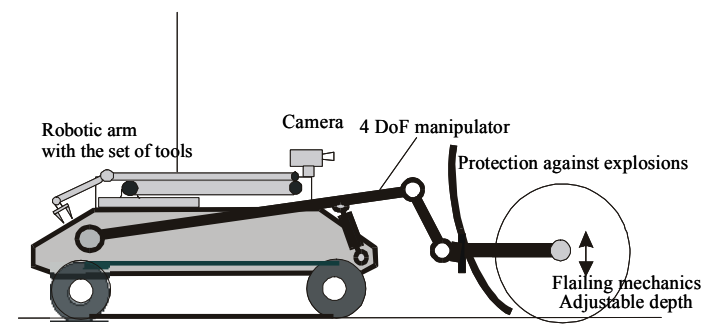

Fig. 4. The robotic flailing vehicle for destruction of mines

- Internal sensors for state monitoring and control of the vehicle and manipulation devices. There are sensors for sensing: pressures, positions of mechanisms, velocities, etc. 
- External detection and sensory systems for sensing / monitoring environment (global position sensing - GPS, multi- sensorial mine detection / recognition systems, vehicle navigation, obstacles, etc.)

- Sophisticated communication and control systems. The vehicle control system includes navigation and mobility control. As regards to navigation the vehicle operates within the global world coordinates measured by GPS or within local references defined on place. Control of robot arm is considered to be in local world or tool reference coordinates. Global control scheme of the system shows Fig.5.

- An operation / control center with monitoring devices.

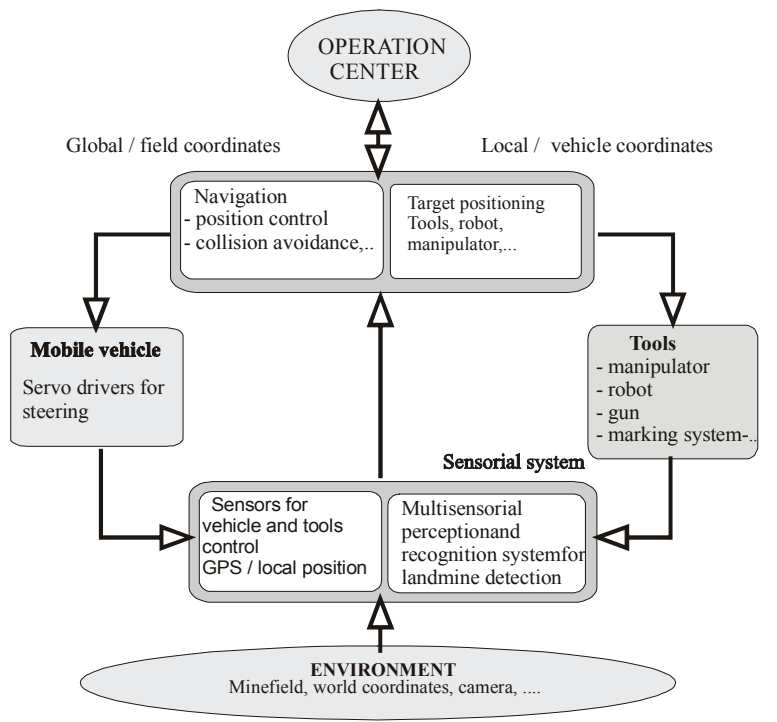

Fig. 5 . Global control scheme of the robotic vehicle for demining operations

\section{Further Development of Demining Machines}

\subsection{Design and System Description}

As discussed in (Havlik, 2007) there are several criteria should be taken into account and standards (CEN, 2004) that any vehicle for mechanical demining should satisfy. On the example of Božena machines further research and development of vehicles with mechanical activation technology is shown.

"Božena 4" in Fig. 6, is the fourth generation of the mini-flail vehicles mainly oriented for clearing large areas from antipersonnel mines (AP) as well as from anti-tank (AT) mines up to $9 \mathrm{~kg}$ of TNT equivalent.

The last generation machine of this family, "Božena 5", belongs to category of midi-flail systems. This much more powerful machine exhibits about two-times higher productivity of 
cleaning comparable terrains. To reach a good maneuvering capability in various terrains the solution that enables to combine wheels and belts was adopted.
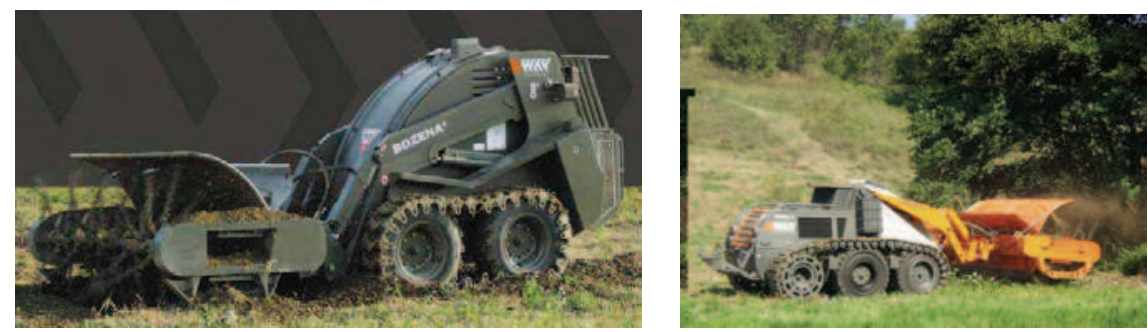

Fig. 6. Božena 4 (left) and Božena 5 (right) in demining action

Control of all mechanisms is realized from the cabin where all data and information about the machine and its environment are transmitted. The operator can use the special portable control box with keyboard and joystick. Some principal control routines are preprogrammed.

To improve controllability of vehicle actions the on-board remote vision system has been developed and can be installed. In the most complex configuration it consists of two stable cameras for observation the environment in front and in rear of the vehicle and one camera fixed on the 2 d.o.f. mechanism, in Fig. 7., which enables adjustable possibility of observation within the whole area $360^{\circ}$ around the vehicle and $+/-20^{\circ}$ tilting. Pictures from cameras are digitally transmitted on screens into the operation center. Thus, combining the visual pictures with GPS data it is possible to recognize actual situation on the minefield (terrain, obstacles, trenches, trees, etc.) and to make correct decisions.
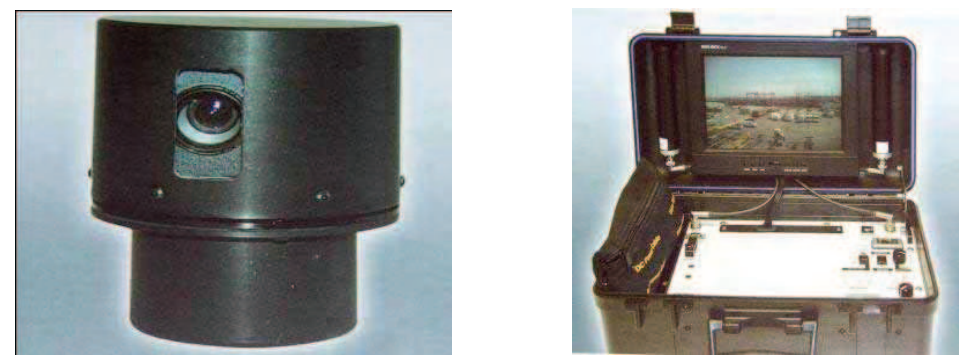

Fig. 7. The robust camera and monitor box of the vision system

In cases when the vehicle can not move due to any serious failures (engine, communication, etc.) it should be removed from the minefield. For this purpose it is equipped by the hydraulic winch - cable mechanism. This simple recovery system enables the machine to be pulled back from a dangerous place. 


\subsection{Tools and Attachments}

Concept of the multi-purpose machine includes two categories of tools and attachments.

There are:

- Equipment directly related to the demining process: platform for detection systems, flailing mechanism, target marking system, saw / cutter of vegetation, system for removing metal parts, grippers, etc.

- Equipment for engineering works as digging, drilling, loading and transport of soil or loose materials, removing obstacles, etc.

Some examples of these accessories have been developed for Božena machines are given in next.

\section{Flailing Mechanism}

The well known flailing principle consists of the rotating shaft with set of chains and hammers on their ends. The crucial problem is to design such a flailing system which keeps maximal efficiency and quality together with high productivity of cleaning process. To achieve this performance many parameters and characteristics should be studied and experimentally verified. Some of them are: length of chains, forms and material of hammers, positions of chains on the shaft, speed of rotation, impact energy of hammers, advance speed with respect to depth of penetration, soil, etc. Beside technical criteria, the mechanism should be very robust to resist explosions of AP mines and possible AT mines too.

The flailing mechanism in Fig. 8 is designed as an independent system powered by two hydro-motors with reverse rotation possibility. The flailing process, including advance speed, shaft rotation speed, depth, copying the terrain, is fully controlled by pre programmed routines.

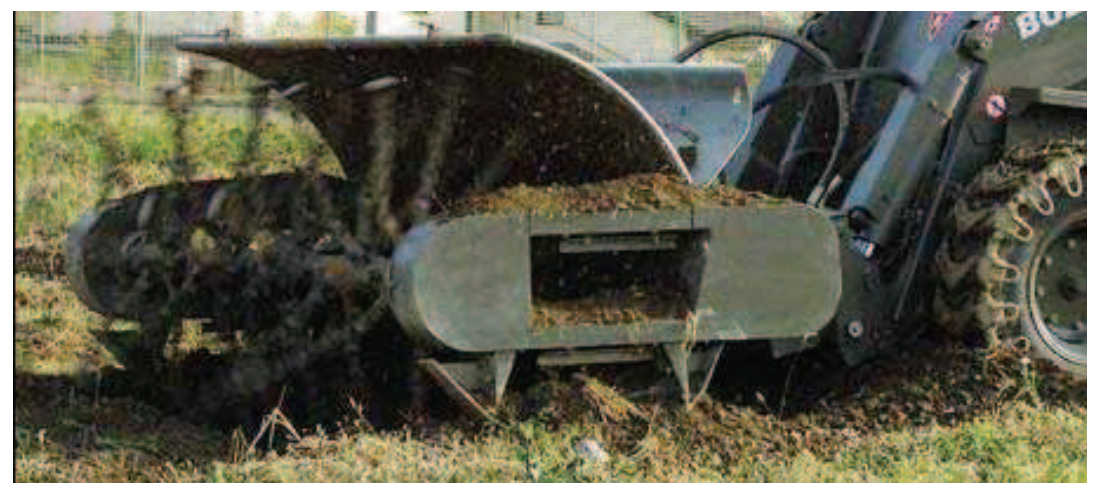

Fig. 8. Flailing mechanism

\section{Collector of Magnetic Parts}

After cleaning process on each minefield are usually spread great numbers of metal parts, such as shells, ammunition cartridges, mine fragments, or other ferromagnetic parts such as wires, screws, etc. Obviously, these spread parts result in false signals of metal detectors when the verification procedure is doing. To pick up all small ferromagnetic parts the special attachment -magnetic collector, in Fig.9, is designed. 


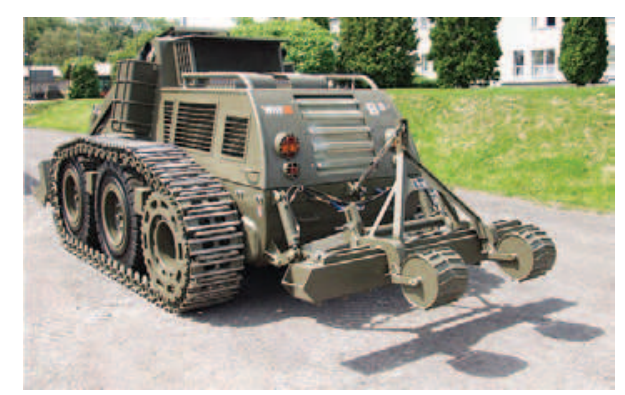

Fig. 9. Magnetic collector

\section{Soil Separator}

Another useful attachment is the mechanism for sifting and recycling soils where AP mines and UXO are expected. This attachment enables to take up the material (soil, waste) and, after closing the drum, by turning motion the content is sifted. The objects, as AP mines, remain inside the drum and may be dumped afterwards after opening the jaw. Grated form of jaws is as well the best solution enables to spread the blast wave in case explosions inside the drum. As the procedure is remotely controlled the safety for operator is provided.

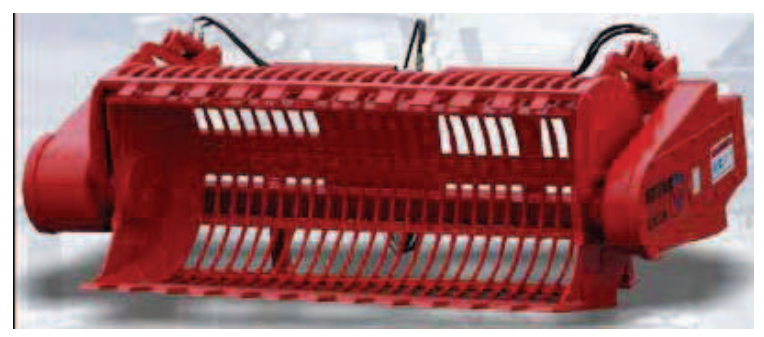

Fig. 10. Separator for sifting and recycling soil

\section{Other Attachments}

Beside direct demining process, there are many dangerous works should be made in remote operation mode. Main reason is to protect persons if any suspicion on explosion or other possible hazard situation could arise. There are several useful accessories that can be directly attached on the end flange of the heavy load manipulator. Some of them frequently applied for most principal works are in Fig.11. 

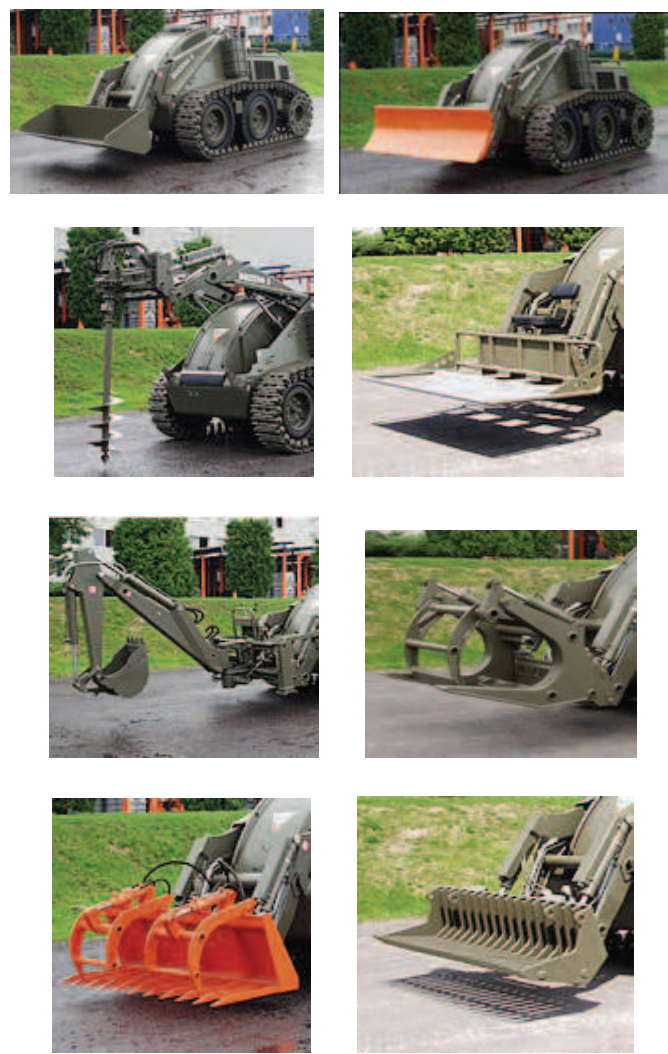

Fig. 11. Some accessories for remotely operated machines

\section{Conclusion}

Considering large polluted areas and drawbacks of actual demining technologies main contributions of using robotic vehicles are expected in following topics:

- Searching large areas and localization of mines and any explosives (UXO) by fast and reliable way.

- Fast and reliable neutralization/destruction of mines without the need of personal assistance to be inside, or close to dangerous places.

Demining process remains and will be still one of the most dangerous operations. For this reason new robotic technologies and detection principles should be applied.

The paper presents a modular concept and on examples describes the robotic vehicles equipped by the flailing activation mechanism and other accessories used in demining process and other civil engineering works.

All activities in dangerous terrains, as minefields, require applying specific approaches to searching, precise localization of single targets, neutralization process and other works, as well. Operations of unmanned vehicles in such terrains suppose that they have some level of autonomy to solve especially critical situations. This is the task for research in the future. 


\section{Acknowledgment}

Author highly appreciates the help of the WAY industry company - Slovakia (www.wayindustry.sk) and will express thanks for information and photo-material used in this article.

\section{References}

GICHD (2006). Mechanical demining equipment catalogue. Geneva Int. Center for Humanitarian Demining. (www.gichd.ch), March 2006, ISBN 2-88487-026-1

GICHD (2004). A study of mechanical application in demining. Geneva Int. Center for Humanitarian Demining. www.gichd.ch, May 2006, ISBN 2-88487-023-7

CEN (2004). Workshop Agreement „Test and evaluation of demining machines." CWA 150 44, July 2004,

Proc. (2007). Proc. on the 4th International Symposium "Humanitarian Demining 2007 Mechanical Demining" 24 - 27 April, Šibenik, Croatia. (to be published in 2007)

Habib, M.K. (2002). Mechanical mine clearance technologies and humanitarian demining. Applicability and Effectiveness. In Proc. 5 th. Int. Symposium on Technology and mine problem. Monterey, CA, USA Apr. 22-25. pp.

Havlík, Š. (2005). A modular concept of robotic vehicle for demining operations. Autonomous Robots, 18, 2005, pp. $253-262$

Havlík Š. (2007). Some robotic approaches and technologies for humanitarian demining. Publ. in this book.

Ide, K. et al. (2004). Towards a semi -autonomous vehicle for mine neutralization. In Proc. International Workshop Robotics and Mechanical assistance in Humanitarian Demining and Similar risky interventions, IARP, Brussels-Leuven, Belgium, June 16-18.

Kaminski, L. et al. (2003). The GICHD Mechanical Application in Mine Clearance Study. Proc. EUDEM2-SCOT -2003 Int. Conf. on Requirements and Technologies for Detection, Removal and Neutralization of Landmines and UXO. Sept. 15-18, Brussel, Belgium, pp.335-341

Licko, P. \& Havlik, S. 1997. The demining flail and system BOZENA. In Proc. International Workshop on Sustainable Humanitarian Demining, SUSDEM 97, Zagreb, Croatia, Sept. 29 - Oct. 1, pp. S4.8-S.4.11.

Lindman, A.R. \& Watts, K.A. (2003). Inexpensive mine clearance flails for clearance of antipersonnel mines. In Proc. EUDEM2-SCOT-2003 Int. Conf. on Requirements and Technologies for Detection, Removal and Neutralization of Landmines and UXO, Brussels, Belgium, Sept. 15-18, pp.356-359.

Stilling, D.S.D., Kushwaha, R.L. \& Shankhla, V.S. (2003). Performance of chain flails and related soil interaction. In Proc. EUDEM2-SCOT -2003 Int. Conf. on Requirements and Technologies for Detection, Removal and Neutralization of Landmines and UXO. , Brussels, Belgium, Sept. 15-18, pp.349-355.

WAY Industry, a.s. (2006). Technical specifications of mine clearance flail systems: BOZENA 4, 5; WAY Industry, a.s., Slovakia 


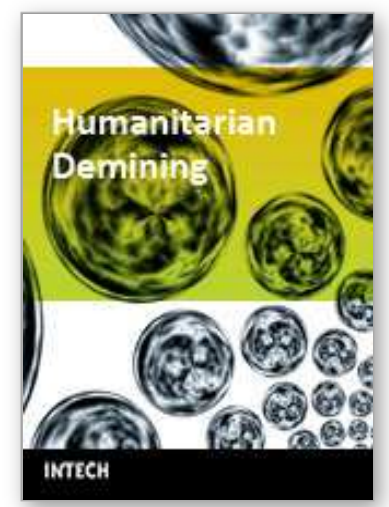

\author{
Humanitarian Demining \\ Edited by Maki K. Habib
}

ISBN 978-3-902613-11-0

Hard cover, 392 pages

Publisher I-Tech Education and Publishing

Published online 01, February, 2008

Published in print edition February, 2008

United Nation Department of Human Affairs (UNDHA) assesses that there are more than 100 million mines that are scattered across the world and pose significant hazards in more than 68 countries. The international Committee of the Red Cross (ICRC) estimates that the casualty rate from landmines currently exceeds 26,000 persons every year. It is estimated that more than 800 persons are killed and 1,200 maimed each month by landmines around the world. Humanitarian demining demands that all the landmines (especially AP mines) and ERW affecting the places where ordinary people live must be cleared, and their safety in areas that have been cleared must be guaranteed. Innovative solutions and technologies are required and hence this book is coming out to address and deal with the problems, difficulties, priorities, development of sensing and demining technologies and the technological and research challenges. This book reports on the state of the art research and development findings and results. The content of the book has been structured into three technical research sections with total of 16 chapters written by well recognized researchers in the field worldwide. The main topics of these three technical research sections are: Humanitarian Demining: the Technology and the Research Challenges (Chapters 1 and 2), Sensors and Detection Techniques for Humanitarian Demining (Chapters 3 to 8 ), and Robotics and Flexible Mechanisms for Humanitarian Demining respectively (Chapters 9 to 16$)$.

\title{
How to reference
}

In order to correctly reference this scholarly work, feel free to copy and paste the following:

Stefan Havlik (2008). Land Robotic Vehicles for Demining, Humanitarian Demining, Maki K. Habib (Ed.), ISBN: 978-3-902613-11-0, InTech, Available from:

http://www.intechopen.com/books/humanitarian_demining/land_robotic_vehicles_for_demining

\section{INTECH}

open science | open minds

\author{
InTech Europe \\ University Campus STeP Ri \\ Slavka Krautzeka 83/A \\ 51000 Rijeka, Croatia \\ Phone: +385 (51) 770447 \\ Fax: +385 (51) 686166 \\ www.intechopen.com
}

\author{
InTech China \\ Unit 405, Office Block, Hotel Equatorial Shanghai \\ No.65, Yan An Road (West), Shanghai, 200040, China \\ 中国上海市延安西路65号上海国际贵都大饭店办公楼 405 单元 \\ Phone: +86-21-62489820 \\ Fax: +86-21-62489821
}


(C) 2008 The Author(s). Licensee IntechOpen. This chapter is distributed under the terms of the Creative Commons Attribution-NonCommercialShareAlike-3.0 License, which permits use, distribution and reproduction for non-commercial purposes, provided the original is properly cited and derivative works building on this content are distributed under the same license. 